\title{
Borehole Breakouts and In Situ Stresses
}

\author{
B. Shen CSIRO Exploration and Mining, Australia
}

\begin{abstract}
This paper describes a study of estimating the magnitude of in situ horizontal stresses from borehole breakout data in a deep geothermal well in Australia. The knowledge of in situ dominates the shape and orientation of the underground heat exchange reservoir.

Extensive borehole breakouts occurred in the granite section (depth $=3650-4421 \mathrm{~m}$ ) of Habanero No. 1 well in Cooper Basin during drilling. The direction and dimension of borehole breakouts were measured using borehole geophysical logging. No direct stress measurements (e.g. hydraulic fracturing) could be conducted in the well due to extraordinary temperature $\left(240^{\circ} \mathrm{C}\right)$ and over-pressure $(35 \mathrm{MPa}$ above hydrostatic pressure conditions). Therefore, the breakout data were the only information available for evaluating the in situ horizontal stresses.

The study was conducted using fracture mechanics numerical code (FRACOD) which can simulate rock fracture initiation and propagation in both intact and jointed rocks. Firstly, a quantitative relation between the breakout dimensions and the magnitude of the in situ stresses in the granitic rock was established by means of the numerical modelling. Then, the in situ stresses were back-analysed using this relation and the measured geophysical borehole breakout data at various borehole depths.
\end{abstract}

The predicted stress ratios from this study were consistent with the seismic monitoring results obtained during the subsequent reservoir stimulation tests. The prediction and monitoring results indicate that both horizontal principal stresses are higher than the vertical principal stress, which is the most favourable stress condition for geothermal reservoirs.

\section{Introduction}

Geothermal energy is a clean energy resource that currently holds strong interests in Australia. Extracting geothermal energy for electricity generation often requires drilling deep boreholes into high temperature rock formations (or hot rocks). By injecting high pressure fluid into the rock formation, the hot rocks will fracture, creating a permeable underground heat exchange reservoir. This is a process called reservoir stimulation. The thermal energy can then be extracted by circulating water through the stimulated reservoir via two or more boreholes.

To achieve the best heat extraction, it is desirable that the heat exchange reservoir is oriented horizontally and hence the heat exchange between rock and fluid is confined in the high temperature rocks. A stress regime with horizontal stresses higher than the vertical stress favours the formation of such reservoir during the simulation process. Therefore, understanding the in situ stress regime is critically important to the geothermal energy operations.

Since the geothermal reservoir is often at a depth greater than several kilometres, direct measurement of the in situ stresses by the conventional methods such as hydraulic fracturing is very difficult. However, it is possible to estimate the in situ stresses indirectly using the data of the borehole breakout, because borehole breakouts occur almost certainly at such depths and the breakout dimension is related to the in situ stress magnitudes.

Borehole breakouts, i.e. failure of the borehole wall due to stress concentrations, result in an elongation of the borehole cross-section in the direction of the minor principal stress. Previous observations and theoretical analyses of borehole breakouts indicated that failure of the borehole wall is often governed by either a tensile spalling or a shear fracturing mode (Vardoulakis et al., 1988; Guenot, 1989). In the case of tensile spalling, the rock breakage starts in the vicinity of a borehole as a result of tensile crack initiation and propagation along the direction of the major principal stress. A series of sub-parallel cracks are formed and the 
coalescence of these tensile cracks makes up a layer which may fall from the borehole wall. This phenomenon is typical for hard crystalline rocks such as granite under compression with either no or small lateral confinement (Ewy and Cook, 1990; Lee and Haimson, 1993; Martin et al., 1994; Haimson and Lee, 1995; Amadei and Stephansson, 1997). In the case of shear fracturing, shear failure along one or more shear bands extends from the borehole wall into the rock. The shear fractures (or shear bands) can cause breakout when they intersect one another. This type of failure is often observed in softer porous rocks, such as dolomite, limestone and sandstone (Zoback et al., 1985; Guenot, 1989). Both failure modes can result in the so called 'dog-ear' shaped breakouts.

Theoretical studies have been conducted to understand and predict the two breakout mechanisms. The breakout by shear was assumed to follow the Mohr-Coulomb failure criterion (Zoback et al., 1985). Although this can explain the wide and shallow breakout shapes sometimes observed in the field, it cannot produce the sharp-edged breakouts corresponding to the 'dog-ear' type.

Extensile cracking has been observed in laboratory uni- or bi-axial borehole tests. Extensile cracking is attributed to the structural instability of the borehole wall. Vardoulakis et al. (1988) and Zheng et al. (1989) implemented a compressive failure criterion in a numerical method and predicted the breakout of 'dog-ear' shape as a result of gradual failure. The results provided a close representation of the phenomenon, but could not explain the physical mechanism of extensile cracking.

A fracture mechanics approach was used by Shen et al. $(1997 ; 2002)$ to predict the breakouts formed by tensile fracturing and shear fracturing, respectively. During these studies, a FRACOD was used and it was demonstrated that the code can realistically simulate the actual process and mechanism of borehole breakouts. This code is used in this study.

This study focuses on the Habanero No. 1 well which was drilled by Geodynamics Ltd at Cooper Basin. It was the first deep well drilled for developing hot fractured rock (HFR) geothermal resource in Australia. The well was drilled to a depth of $4421 \mathrm{~m}$ with bottom hole temperatures of $240^{\circ} \mathrm{C}$. Extensive borehole breakouts occurred in the granite section (depth $=3650-4421 \mathrm{~m}$ ) of Habanero No. 1 well after drilling. The direction and dimension of borehole breakouts were measured using borehole geophysical logging.

The study was conducted in the following steps:

- Establish a quantitative relation between breakout dimensions and in situ stresses in granitic rock by means of numerical modelling.

- Back-calculate the in situ stresses using the measured borehole breakout data at Habanero No. 1 well at various depths.

- Evaluate the overall stress state and stress ratios in Habanero No. 1 well granite.

\section{Numerical modelling of borehole breakouts}

Borehole breakout in granitic rock is often dominated by explicit fracturing. The fracture propagation code FRACOD developed by Shen and Stephansson (1994) and FRACOM (2002) has been shown to effectively simulate the breakout process (Shen et al., 2002). FRACOD was used in this study to predict the breakout dimensions under various stress combinations. FRACOD is a 2D code, and only horizontal planes (perpendicular to the wellbore axis) are considered. The study is aimed at estimating the magnitude of the horizontal stresses only. The vertical stress is assumed to be the gravity load determined from the cover depth and the rock density. The 2D approach is limited to the case that the principal stresses are vertical and horizontal. Where the two principal stresses are not in the vertical and horizontal planes, particularly nearly the major fracture zone, errors may result from the $2 \mathrm{D}$ assumption.

The numerical code uses a modified strain energy release rate criterion, F-Criterion (Shen and Stephansson, 1994), to detect fracture propagation. A probabilistic approach is used to detect the fracture initiation which may occur at a stress level well below the rock strength (FRACOM, 2002). 


\subsection{Input properties}

The mechanical properties required in this study include the intact rock strength, fracture contact properties and fracture toughness. Due to the lack of directly measured data of the Habanero No. 1 granite, the mechanical properties used in this study are mostly based on previous modelling experience for granitic rock properties (Stephansson et al., 2003). Some modifications of the data were made after limited sensitivity studies to reproduce the breakout shape observed in the AECL experimental tunnel (Martin et al., 1997). The values of the mechanical properties used in this study are listed in Table 1.

Table 1 Summary of mechanical properties used in the model

\begin{tabular}{ll}
\hline Mechanical Properties & \\
\hline Intact rock strength: & \\
Young's modulus & $65 \mathrm{GPa}$ \\
Poisson's ratio & 0.25 \\
Cohesion & $31 \mathrm{MPa}$ \\
Friction angle & $35^{\circ}$ \\
Uniaxial compression strength $\left(\sigma_{\mathrm{c}}\right)$ & $120 \mathrm{MPa}$ \\
\hline Fracture toughness: & \\
Mode I toughness & $1.35 \mathrm{MPa} \mathrm{m}{ }^{1 / 2}$ \\
Mode II toughness & $3.07 \mathrm{MPa} \mathrm{m}{ }^{1 / 2}$ \\
\hline John/fracture properties: & \\
Normal stiffness Kn & $50,000 \mathrm{GPa} / \mathrm{m}$ \\
Shear stiffness Ks & $12,550 \mathrm{GPa} / \mathrm{m}$ \\
Friction & $25.5^{\circ}$ \\
Cohesion & 0 \\
Dilation angle & $2^{\circ}$ \\
\hline
\end{tabular}

The fracture properties are found to have minor effects on the results once they are fallen into a range (i.e. the stiffness values are high enough and the friction angle is low enough). The chosen values above are considered to be reasonable based on the previous modelling experience in granite at Tono Mine in Japan and the diorite at Äspö Hard Rock Laboratory in Sweden.

\subsection{Modelling results}

Borehole breakouts are predicted numerically in the following steps: (1) Setting up the numerical model including defining borehole geometry, rock properties and in situ stresses; (2) FRACOD automatically calculates stresses in the borehole walls using solid mechanics principles; (3) FRACOD then determines if any failure (fracture initiation) occurs in the borehole wall based on the stresses obtained and the rock strength; (4) If failure is detected to occur, new fractures will be generated in the model and FRACOD then determines if and how they propagate; (5) Breakouts will be formed when fractures in the borehole wall propagate and coalesce. (6) The dimensions of the final breakouts are obtained when there is no further failure and fracture propagation in the borehole wall.

Fifteen cases with different combinations of the major and minor principal horizontal stresses $\left(\sigma_{\operatorname{Hmax}}\right.$ and $\left.\sigma_{\text {hmin }}\right)$ were simulated, see Table 2 . The modelled magnitude of $\sigma_{H \max }$ and $\sigma_{\text {hmin }}$ varies in the range of 50-80 MPa and 10-60 MPa, respectively. The stress ratio $\sigma_{\mathrm{Hmax}} / \sigma_{\mathrm{hmin}}$ varies in the range of 1.2-8.0. Note that the stresses used in the numerical modelling are effective stresses and no pore pressure is considered at this stage. 
Figure 1 shows a typical set of the modelling results. The breakout angle is defined as the azimuth angle of the breakout at the borehole wall, the breakout depth is defined as the distance between the tip of the breakout to the original borehole wall. Several observations can be made based on the modelling results:

- For a given $\sigma_{H \max }$, a lower $\sigma_{\mathrm{hmin}}$ is found to result in a deeper breakout. Because the variation of $\sigma_{\mathrm{hmin}}$ affects the stress ratio $\sigma_{H \max } / \sigma_{\text {hmin }}$ much more severely than an overall average stress (for example $\left.\left(\sigma_{\mathrm{Hmax}}+\sigma_{\mathrm{hmin}}\right) / 2\right)$, it implies that the depth of the breakout is very much dependent on the stress ratio $\sigma_{\mathrm{Hmax}} / \sigma_{\mathrm{hmin}}$, rather than an average stress index.

- For a given $\sigma_{\mathrm{hmin}}$, a higher $\sigma_{\mathrm{Hmax}}$ will result in a wider breakout, implying that the width (or azimuth angle) of the breakouts depends on the magnitude of the major horizontal principal stress.

- Breakouts are caused by combined tensile and shear fracturing. The initial fracturing starts at the borehole wall and propagates into the rock. Some failures also initiate inside the borehole wall during breakout development.

Table 2 Summary of modelling results

\begin{tabular}{cccc}
\hline $\begin{array}{c}\sigma_{\text {Hmax }} \\
(\mathrm{MPa})\end{array}$ & $\begin{array}{c}\sigma_{\text {hmin }} \\
(\mathrm{MPa})\end{array}$ & $\begin{array}{c}\text { Breakout Angle } \\
\left({ }^{\circ}\right)\end{array}$ & $\begin{array}{c}\text { Normalised Breakout Depth } \\
(\% \text { of borehole radius })\end{array}$ \\
\hline 80 & 60 & 117 & $28 \%$ \\
80 & 40 & 90 & $31 \%$ \\
80 & 25 & 81 & $37 \%$ \\
80 & 10 & 72 & $32 \%$ \\
70 & 50 & 86.4 & $24 \%$ \\
70 & 30 & 72 & $24 \%$ \\
70 & 15 & 72 & $26 \%$ \\
60 & 50 & 64.8 & $16 \%$ \\
60 & 40 & 57.6 & $14 \%$ \\
60 & 30 & 57.6 & $26 \%$ \\
60 & 20 & 64.8 & $20 \%$ \\
60 & 11 & 57.6 & $29 \%$ \\
50 & 30 & 14.4 & $5 \%$ \\
50 & 20 & 36 & $20 \%$ \\
50 & 10 & 43.2 & $24 \%$ \\
\hline
\end{tabular}

Note that the results for some cases are off the trend, due to the randomness in the fracture initiation and propagation process. 


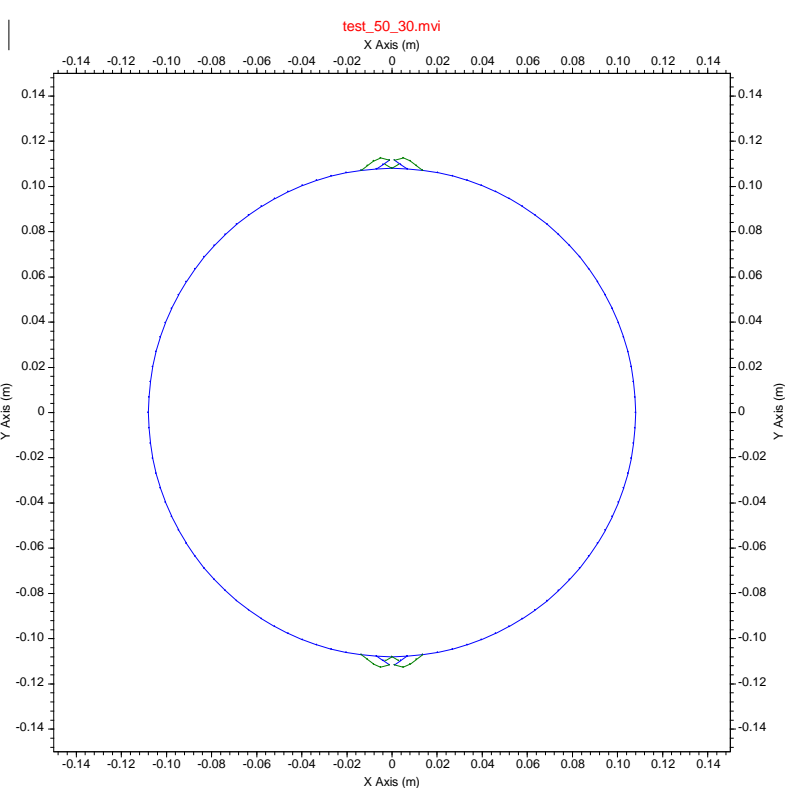

(a) $\sigma_{\mathrm{Hmax}}=50 \mathrm{MPa}, \sigma_{\mathrm{hmin}}=30 \mathrm{MPa}$

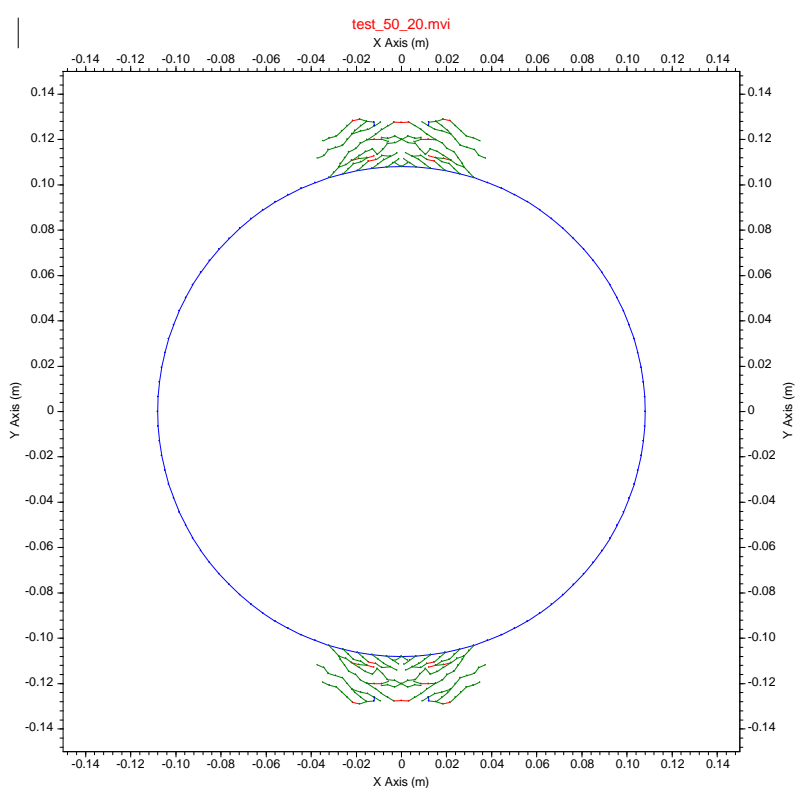

(b) $\sigma_{\text {Hmax }}=50 \mathrm{MPa}, \sigma_{\mathrm{hmin}}=20 \mathrm{MPa}$

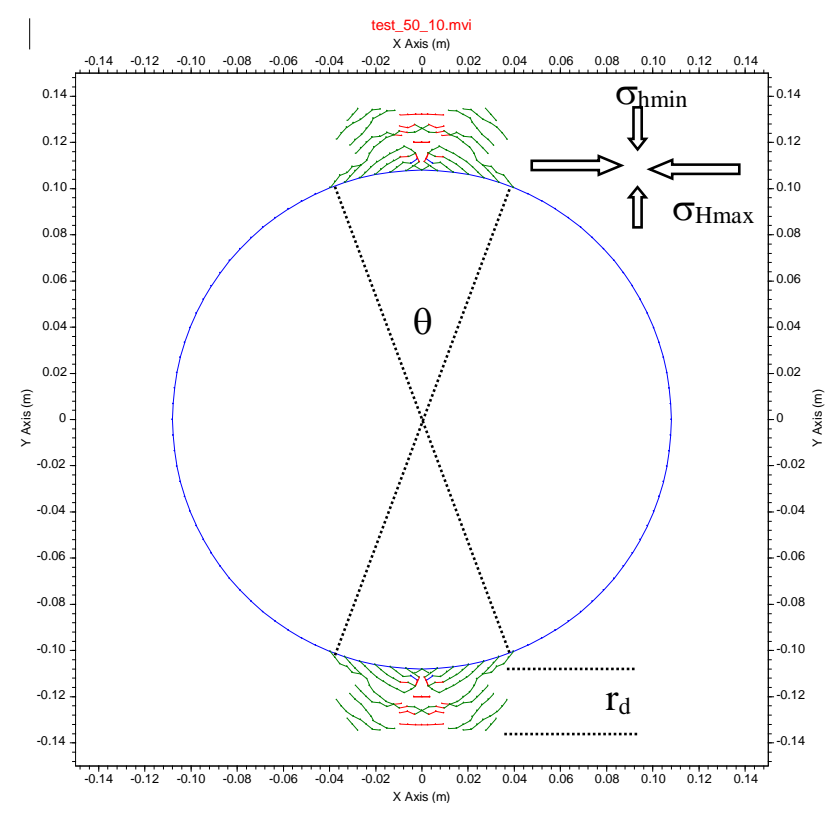

(c) $\sigma_{\mathrm{Hmax}}=50 \mathrm{MPa}, \sigma_{\mathrm{hmin}}=10 \mathrm{MPa}$

Figure 1 Predicted borehole breakouts at $\sigma_{H \max }=50 \mathrm{MPa}$ and different $\sigma_{\mathrm{hmin}}$. The definition of the breakout angle $(\theta)$ and depth $\left(\mathbf{r}_{d}\right)$ is also shown

\section{Back-analysis of horizontal stress magnitude}

The modelling results listed in Table 2 are analysed to establish the correlations between the stress magnitude and the breakout dimensions. The relations will be used to estimate the stress magnitudes using the measured breakout dimensions.

\subsection{Correlations between stress/strength ratio and breakout angle}

For a perfect borehole without fracturing, the tangential stress at the borehole wall can be determined using elasticity theory. The azimuth angle within which the tangential stress exceeds the uniaxial compressive strength can be calculated from Equation (1). 


$$
\frac{1-\left(\sigma_{H \text { max }}+\sigma_{h \text { min }}\right) / \sigma_{c}}{2\left(\sigma_{H \text { max }}-\sigma_{h \text { min }}\right) / \sigma_{c}}=\cos (\theta)
$$

Where:

$\theta=$ breakout angle at the borehole wall $\left({ }^{\circ}\right)$.

$\sigma_{\mathrm{c}}=$ uniaxial compressive strength of rock (MPa).

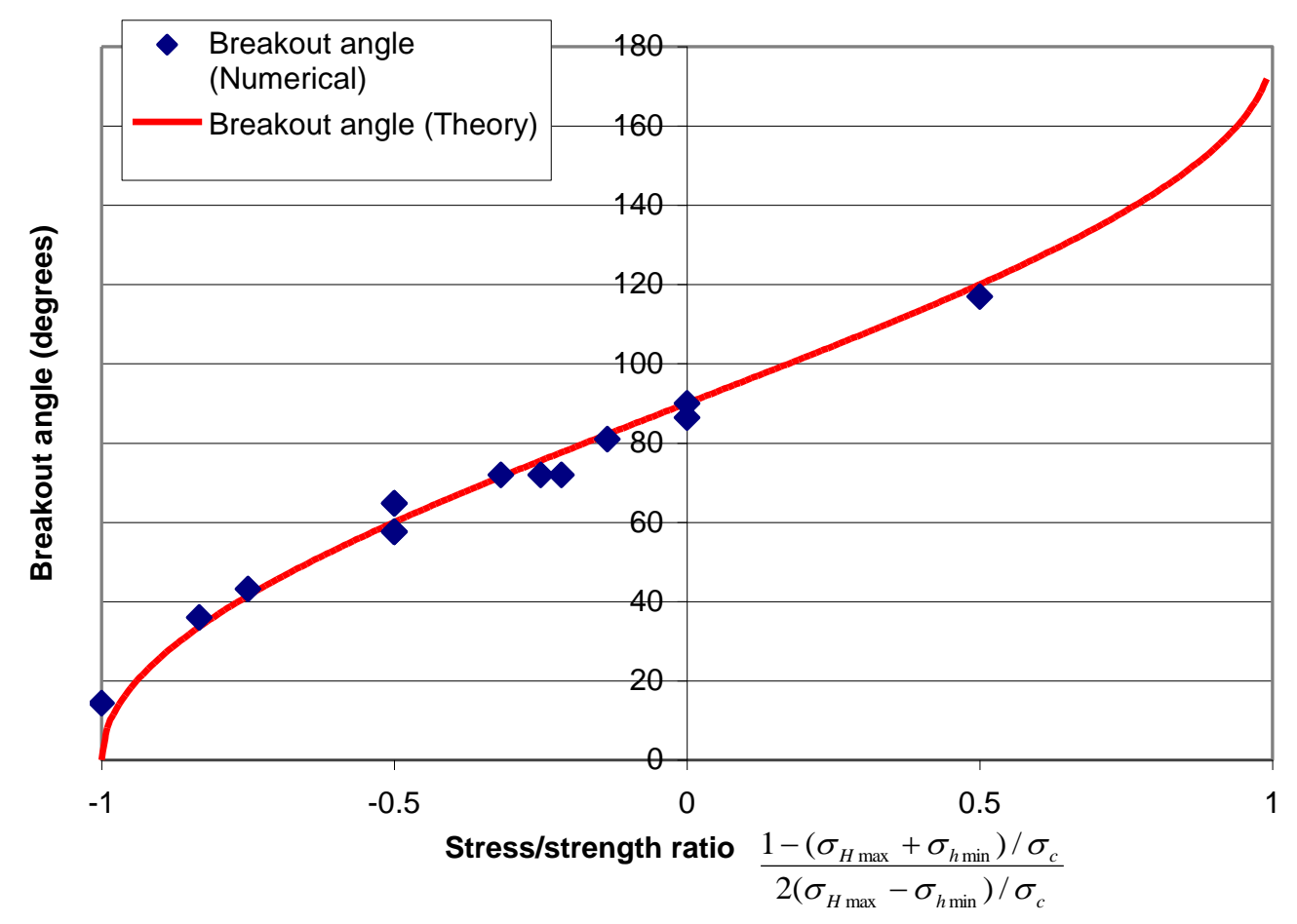

Figure 2 Predicted relationship between stress/strength ratio and the breakout angle

The numerical method used in this study takes into account the effect of progressive fracturing which the analytical method does not consider. FRACOD does not incorporate Equation (1) in its formulation. Rather, it is based on fundamental solid mechanics and fracture mechanics principles. The numerically predicted breakout angles are plotted against the stress/strength factor in the left side of Equation (1), and they are compared with the analytical results, see Figure 2 . The numerical results agree well with the analytical results, suggesting that the breakout angle is not significantly affected by the fracturing process. Rather it is dominated by the initial stress distribution at the borehole wall.

\subsection{Correlations between stress/strength ratio and breakout depth}

The normalised depth of the breakout (breakout depth/borehole radius) is found to have a reasonable correlation with the ratio of maximum tangential stress at the borehole and the rock uniaxial compressive strength, see Figure 3. However, there are noticeable variations in the numerical results from the average correlation curve (Figure 3), possibly due to the limitations in the control of the numerical accuracy and the variation due to randomness of fracture initiation and propagation. To take into account the variations, we consider the average as well as the upper and lower limits of the stress ratio/breakout depth relationship, as given in Equation (2).

$$
\left(3 \sigma_{H \max }-\sigma_{h \min }\right) / \sigma_{c}=1+A\left[\frac{r_{d}}{r}\right]^{B}
$$


Where:

$\mathrm{r}_{\mathrm{d}}=$ depth of breakouts measured from the original borehole wall.

$\mathrm{r}=$ original radius of the wellbore.

$\mathrm{r}_{\mathrm{d}} / \mathrm{r} \quad=$ "normalised breakout depth".

$\mathrm{A}, \mathrm{B}=$ the regression parameters to define the three curves in Figure 3.

Their values are: $\mathrm{A}=15.2, \mathrm{~B}=2.67$ (Average curve); $\mathrm{A}=21.2, \mathrm{~B}=3.33$ (Upper limit curve); $\mathrm{A}=12.6$, $\mathrm{B}=2.22$ (Lower limit curve), respectively.

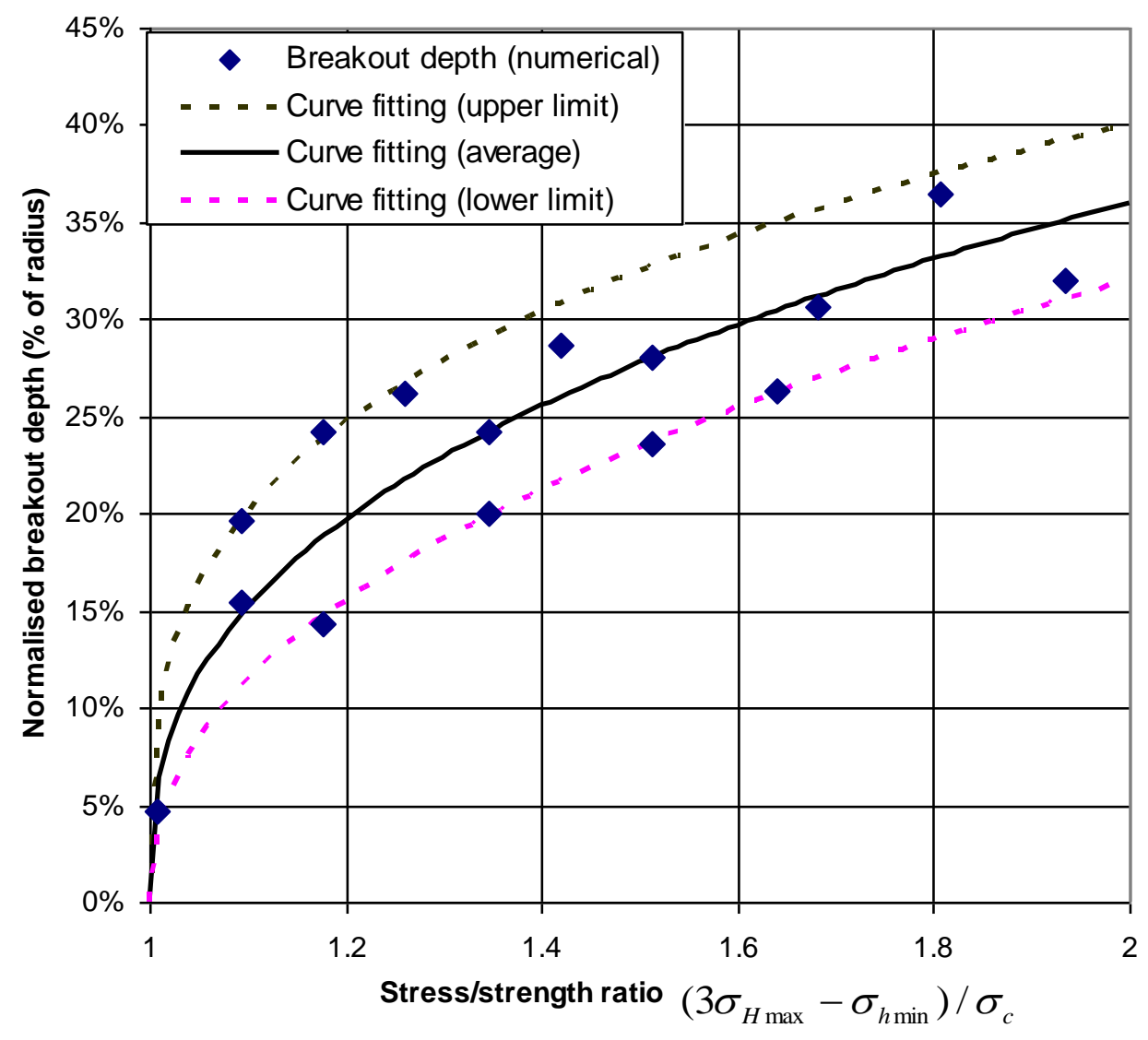

Figure 3 Predicted relationship between stress/strength ratio and the normalised breakout depths

\subsection{Back-analysis of the magnitude of principal horizontal stresses}

When the breakout angle and depth are known, the magnitude of the major and minor horizontal principal stresses can be obtained by solving the systematic equations defined by Equations (1) and (2).

$$
\begin{gathered}
\sigma_{H \text { max }}=\frac{1+(1-2 \cos (\theta))\left(1+A\left[\frac{r_{d}}{r}\right]^{B}\right)}{4(1-\cos (\theta))} \sigma_{c} \\
\sigma_{h \text { min }}=3 \sigma_{H \text { max }}-\left(1+A\left[\frac{r_{d}}{r}\right]^{B}\right) \sigma_{c}
\end{gathered}
$$

The above equations can then be used to calculate the magnitude of the horizontal stresses in the Habanero No. 1 granite, using the measured breakout dimensions. For each cross section, three stress states will be 
given: the average, higher, and lower stress state. The uncertainty of the estimated stress state is taken into account by the lower and upper limit values.

\section{Stress state in the Habanero No. 1 granite}

Borehole breakouts in the Habanero No. 1 granite have been surveyed using geophysical logging tools. The geophysical logging data were used to extract the breakout angle and depth in a number of locations along the wellbore in the granite section. The selected locations are those considered to have a representative borehole breakout angle and depth for a considerable length of the wellbore. They are also intended to cover the whole length of the granite section in the wellbore.

Table 3 Measured borehole breakout dimensions at different depths

\begin{tabular}{ccc}
\hline $\begin{array}{c}\text { Depth } \\
(\mathrm{m})\end{array}$ & $\begin{array}{c}\text { Breakout Angle } \\
\left({ }^{\circ}\right)\end{array}$ & $\begin{array}{c}\text { Normalised Breakout } \\
\text { Depth }\left(\mathrm{r}_{\mathrm{d}} / \mathrm{r}\right)\end{array}$ \\
\hline 3728 & 67 & $6 \%$ \\
3743 & 61.7 & $8 \%$ \\
3776 & 72 & $13 \%$ \\
3810 & 61 & $9 \%$ \\
3885 & 66.8 & $14 \%$ \\
3923 & 61.7 & $18 \%$ \\
3968 & 61.7 & $24 \%$ \\
3996 & 66.9 & $17 \%$ \\
4033 & 61.7 & $18 \%$ \\
4109 & 61.7 & $18 \%$ \\
4121 & 72 & $22 \%$ \\
4142 & 72 & $15 \%$ \\
\hline
\end{tabular}

To provide a statistical trend on stress distribution over the entire length of granite section, a reasonable number of cross sections at different depths need to be investigated. In this study, a total of thirteen cross sections were selected to back-analyse the stress states. Figure 4 shows a typical image of the geophysical survey of the wellbore. For each cross section, the breakout angle was measured from the images, whereas the depth of the breakout was obtained from the calliper logging results. Table 3 lists the measured breakout dimensions of all thirteen cross sections.

After obtaining the breakout angle and depth, Equations (3) and (4) were used to calculate the magnitude of the horizontal stresses. Note that the calculated stresses are the effective stresses. To calculate the total stresses, it was assumed that the pore pressure in granite is equal to the mud pressure equivalent to a mud density of $1800 \mathrm{~kg} / \mathrm{m}^{3}$ which was used during drilling below the depth of $4135 \mathrm{~m}$. This gives a mud pressure of $74.1 \mathrm{MPa}$ at the depth of $4209 \mathrm{~m}$.

For each case, the average value, upper and lower limits are given to consider the uncertainty. The predicted horizontal stresses are plotted in Figure 5. The predicted stress variation with depth and the stress ratios are given below. Note that all the back-analysed stresses presented thereafter are total stresses, i.e. the sum of the effective stress and the pore pressure $=$ mud pressure. 


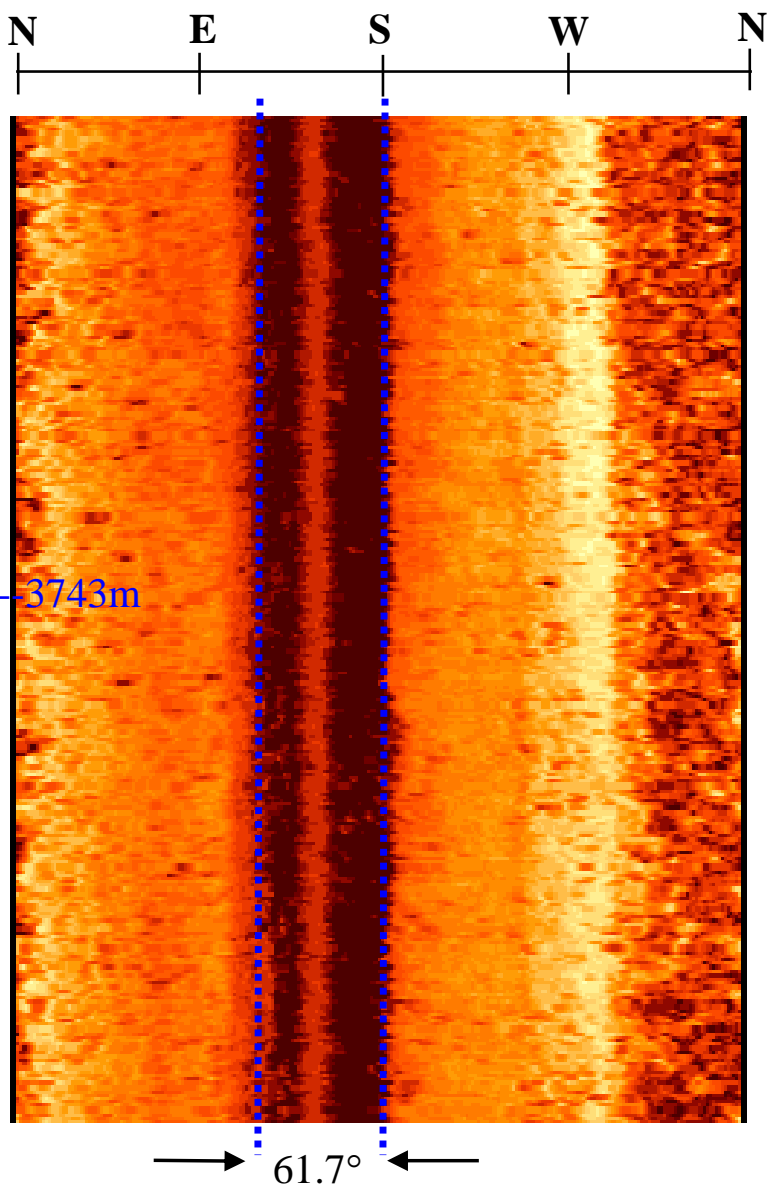

Figure 4 Image of the geophysical survey of the wellbore at depth of $3743 \mathrm{~m}$. The breakout angle was measured from the images, whereas the depth of the breakout was obtained from the calliper logging results (not shown in this Figure)

The vertical stress was estimated based on the study results by Hill et al. (1997) in this area for the sediments, plus a density of $2670 \mathrm{~kg} / \mathrm{m}^{3}$ for the granite.
Major horizontal principal stress:
$\sigma_{\text {Hmax }}($ total $)=(0.033 \sim 0.034) \cdot \mathrm{D}$
Minor horizontal principal stress:
$\sigma_{\text {hmin }}($ total $)=(0.028 \sim 0.032) \cdot \mathrm{D}$
Vertical stress:
$\sigma_{\mathrm{v}}($ total $)=0.023 \cdot \mathrm{D}$
Stress ratio:
$\sigma_{\text {Hmax }} / \sigma_{\text {hmin }} / \sigma_{\mathrm{v}}($ total $)=(1.43 \sim 1.48) /(1.22 \sim 1.39) / 1.00$

$\mathrm{D}$ is the depth in metres. 

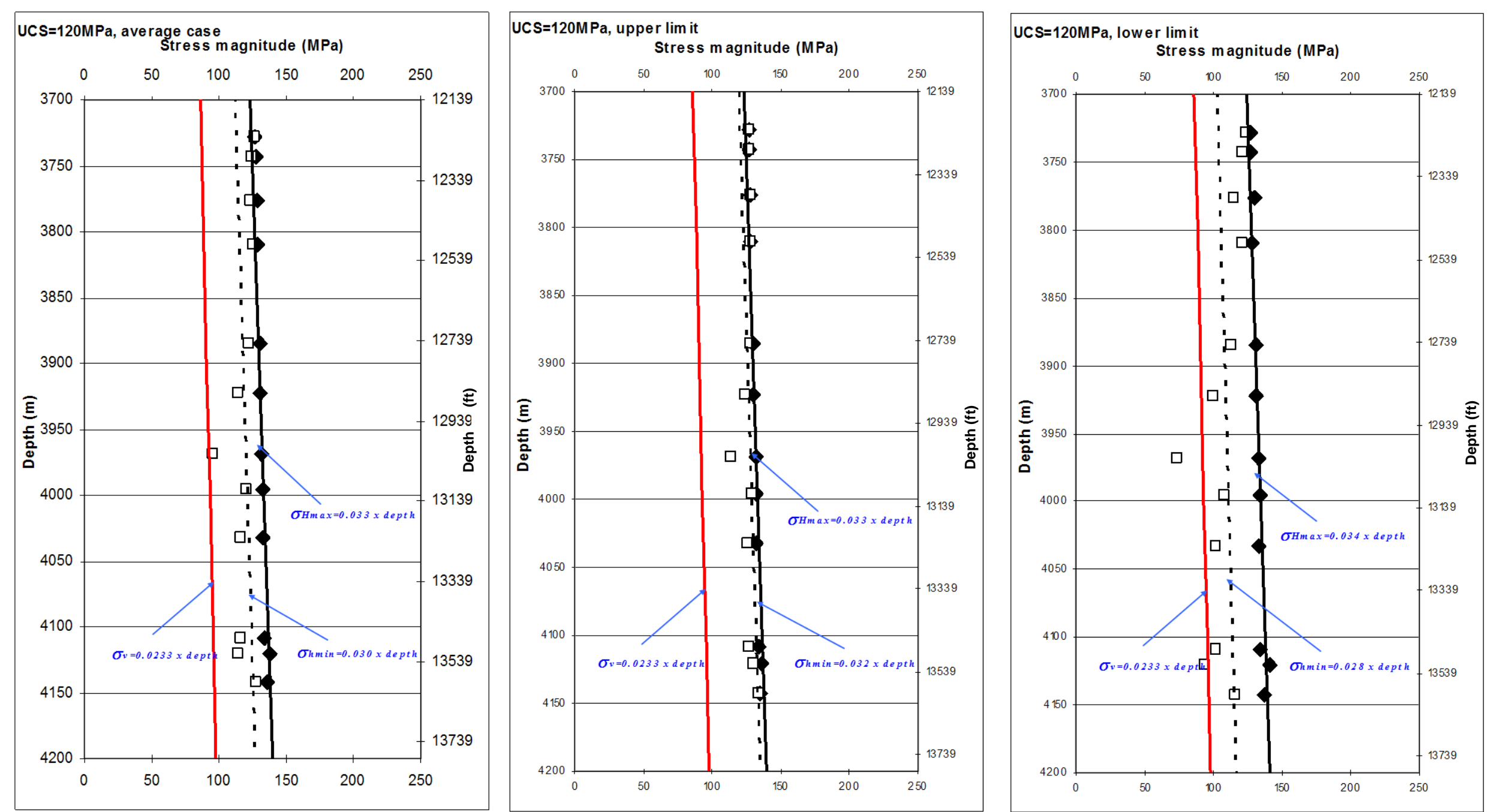

Figure 5 Predicted in situ stress state in granite section of Habanero No. 1 well 


\section{$5 \quad$ Discussion and conclusions}

The study was an attempt to estimate the magnitude of the horizontal stresses using borehole breakout dimensions at the Habanero No. 1 well site. The results of this study highlight the following two key conclusions:

- It is likely that the major and minor principal horizontal stresses are both higher than the vertical stress in the granitic rock at the Habanero No. 1 well site.

- The ratio of the horizontal stresses to vertical stress is expected to fall into the range of $\sigma_{\text {Hmax }} / \sigma_{\text {hmin }} / \sigma_{\mathrm{v}}=(1.43 \sim 1.48) /(1.22 \sim 1.39) / 1.00$. There is a degree of uncertainty particularly in the ratio of $\sigma_{\mathrm{hmin}} / \sigma_{\mathrm{v}}$.

The predicted stress magnitudes only represent the overall stress state in the Habanero No. 1 granite. Local stress concentration or release is likely to exist and is observed as excessive breakouts or no breakouts in some sections of the wellbore.

The predicted stress magnitudes are consistent with the actual observations at Habanero No. 1 well. During the actual reservoir stimulation test conducted afterwards, the seismic monitoring indicated that fractures dipping $20^{\circ}$ in the East and West directions experienced movement. This is a strong indication that both horizontal principal stresses are higher than the vertical stress, which results in sub-horizontal failures planes in the heat reservoir.

The predicted stress ratios from this study have been used to model the fracture movement at Habanero No. 1 well during a well stimulation tests (i.e. wellbore injection tests) in a separate study (Shen, 2004). It was found that the predicted stress state would lead to the slippage of sub-horizontal fractures dipping to the East or West when high pressure fluid is injected from the wellbore. The modelling results further demonstrate that stress state obtained from this study is likely to reflect the true stress state at the Habanero No. 1 granite.

The stress ratios obtained from this study are important to the design of the heat exchange reservoir. The vertical stress, being the minimum stress, implies that fracture movement and fluid flow are most likely to extend in a sub-horizontal direction. This is an ideal situation to achieve an optimal heat exchange using a maximum distance between the injection and production wells.

This study demonstrates that it is feasible to use the borehole breakout dimension to estimate the magnitude of in situ stress if proper models are used that capture the real breakout mechanisms. The results, however, are sensitive to a number of parameters such as rock strength, fracture properties, etc. This method may only give us a likely range of the in situ stress magnitude rather than a definite value as often obtained from the hydraulic fracturing.

\section{Acknowledgements}

The study was jointly sponsored by Geodynamics Ltd and CSIRO. The author wishes to thank Dr Doone Wyborn of Geodynamics Ltd and Mr Steve Davidson for their input to this study.

\section{References}

Amadei, B. and Stephansson, O. (1997) Rock Stress and Its Measurement, Chapman and Hall, London, 490 p.

Ewy, R.T. and Cook, N.G.W. (1990) Deformation and Failure Around Cylindrical Openings in Rock. International Journal of Rock Mechanics and Mining Sciences and Geomechanics Abstracts, 27, pp. 387-427.

FRACOM (2002) FRACOD Version 1.1, User's manual, FRACOM Ltd.

Guenot, A. (1989) Borehole Breakouts and Stress Fields, International Journal of Rock Mechanics and Mining Sciences and Geomechanics Abstracts, 26, pp. 185-195.

Haimson, B.C. and Lee, M.Y. (1995) Estimating In Situ stress conditions from borehole breakouts and core disking experimental results in granite, International Workshop on Rock Stress Measurement at Great Depth, September 30, Tokyo, Japan, pp. 19-24.

Hill, R.R., Meyer, J.J. and Magee, M.E. (1997) The contemporary Stress Field of the Nappamerri Trough and Its Implications for Tight Gas Resources, Report of Department of Geology and Geophysics, University of Adelaide, Australia. 
Lee, M.Y. and Haimson, B.C. (1993) Laboratory study of borehole breakouts in Lac du Bonnet granite: a case of extensile failure mechanism, International Journal of Rock Mechanics and Mining Sciences and Geomechanics Abstracts, 30, pp. 1039-1045.

Martin, C.D., Martino, J.B. and Dzik, E.J. (1994) Comparison of borehole breakouts from laboratory and field tests, in: Proceeding on Rock Mechanics in Petroleum Engineering, Delft, Balkema, Rotterdam, pp. 183-190.

Martin, C.D., Read, R.S. and Martino, J.B. (1997) Observations of Brittle Failure Around Circular Test Tunnel, International Journal of Rock Mechanics and Mining Sciences, Vol. 34, No. 77, pp. 1065-1073.

Shen, B. and Stephansson, O. (1994) Modification of the G-criterion of crack propagation in compression, International Journal of Engineering Fracture Mechanics, Vol. 47(2), pp. 177-189.

Shen, B., Tan, X., Li, C. and Stephansson, O. (1997) Simulation of borehole breakout using fracture mechanics models, In: Rock Stress, Sugawara and Obara (editors), Balkema, Rotterdam, pp. 289-298.

Shen, B., Stephansson, O. and Rinne, M. (2002) Simulation of Borehole Breakouts Using FRACOD2D, Oil and Gas Science and Technology - Rev., IFP, Vol. 57 (5), pp. 579-590.

Shen, B. (2004) Understanding the effects of initial injection pressure on fracture movement at Habanero No. 1 HDR well, CSIRO Exploration and Mining Report 1188C.

Stephansson, O., Shen, B., Rinne, M., Backers, T., Koide, K., Nakama, S., Ishida, T., Moro, Y. and Amemiya, K. (2003) Geomechanical evaluation and analysis of research shafts and galleries in MIU Project, Japan, Proceedings 1st International Symposium on Underground Environment, March, Kyoto, Japan, pp. 39-49.

Vardoulakis, J., Sulem, J. and Guenot, A. (1988) Borehole instabilities as bifurcation phenomena, International Journal of Rock Mechanics and Mining Sciences and Geomechanics Abstracts, 25, pp. 159-170.

Zheng, Z., Kemeny, J. and Cook, N.G.W. (1989) Analysis of borehole breakouts, Journal of Geophysical Researches, 94(B6), pp. 7171-7182.

Zoback, M.D., Mooss, D., Mastin, L. and Anderson, R. (1985) Wellbore breakout and in situ stress, Journal of Geophysical Researches, 90(B7), pp. 5523-5530. 